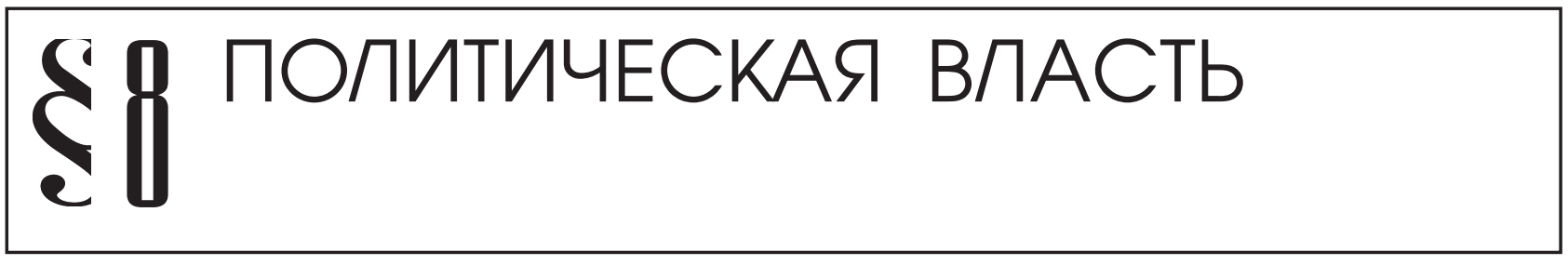

Водопетов C.B.

\title{
РОЛЬ ЭЛИТЫ В КОНТЕКСТЕ ПРИНЯТИЯ ПОЛИТИЧЕСКОГО РЕШЕНИЯ
}

Аннотация: Политическая этика является одним из наиболее важных концептов, лежащих в основе понимания государственного устройства и взаимоотношений между государственным механизмом и общественной структурой. Следование принциипам моральной политики даёт нам понимание того, какую роль играет общество в принятии политических решений и того, что лежит в основе действий тех или иных политических актеров. Актуальность политической этики заключается в вопросах взаимоотношения людей, которые сталкиваются интересами и их возможными примирениями на началах, которые можно было бы назвать «началами добра либо справедливости» При анализе различных моделей формирования государственной политики ключевым критерием будет выступать степень открытости данного процесса и характер взаимоотношений между государством и институтами гражданского общества. Вывод: на сегодняшний день единого и универсального института принятия решений в Российской федерации не выявлено. А модернизация требует новых решений. Важно учитывать, что сейчас власть все чаще сталкивается с ситуацией, когда она не в состоянии сама сформулировать запрос на изменения, как это было в момент экономического кризиса, когда только спустя почти полгода были приняты меры по насыщению ликвидностью.

Review: Political ethics is one of the most important concepts lying in the basis of understanding of the state structure and relations between the state mechanism and social structure. Observance of the principles of moral policy gives us an insight into what lies in the basis of actions performed by these or those political actors. Political ethics is a topical issue because it deals with the relations between people who have opposite interests but who can still get along based on the principles of 'the good or justice'. When analyzing different models of the state policy formation, the author underlines the degree of openness of the process and the nature of mutual relations between the state institution and civic institutions. Conclusion: at the present time there is no single or universal decision making institution in the Russian Federation. Modernization requires new decisions. It is important to take into account that today's government often faces a situation when it cannot formulate the request for change. The same situation happened when the economic crisis began and only half a year later adequate measures were undertaken.

Ключевые слова: Политология, элита, этика, интересы, общественный институт, поведение, мораль, принятие решений, регуляторы, демократия.

Keywords: political science, elite, ethics, interests, social institution, behavior, morals, decision making, regulators, democracy.

A ктуальность политической этики заключается в вопросах взаимоотношения людей, которые сталкиваются интересами и их возможными примирениями на началах, которые можно было бы назвать «началами добра либо справедливости» ${ }^{1}$.

${ }^{1}$ Сутор Б. Политическая этика // Полис. 1993. №1. С. 64.
Прежде всего, необходимо определить само понятие «этика». Под этикой мы понимаем «общественный институт, который выполняет функцию регулирования человеческого поведения с позиций его моральной оценки» ${ }^{2}$. Из этого определения можно

\footnotetext{
${ }^{2}$ Оболонский А. В. Политическая этика, власть, право // Вопросы гос. и муниц. управления. 2007. Т. 1. №.1. С. 54
} 
вывести и понятие политической этики, которое мы понимаем как прикладной регулятор деятельности лица, обладающего властными полномочиями и соотнесение его действий с общепризнанными и распространёнными в обществе ценностями и правилами поведения. Исключать этический аспект из сферы политики нельзя, поскольку именно он определяет границу между политикой в её истинном смысле и политиканством, политическим интриганством ${ }^{3}$. В целом, можно сказать, что сама «легитимность политики как рода деятельности в принципиально большей мере, чем любого другого рода деятельности, держится на моральных аргументах» ${ }^{4}$.

В представительной демократии, в качестве регуляторов политического поведения выступает само общество. Этот внешний инструмент регулирования позволяет сделать политический процесс прозрачным, а также задаёт определённые рамки в виде моральных принципов и ценностей, принятых в обществе. Не менее важным является внутренний инструмент регулирования - самосознание должностного лица, определяющее человеческое поведение на основании его глубинных убеждений. Этот внутренний регулятор играет существенную роль, поскольку в ситуации несправедливого по отношению к общественным интересам законодательства, он позволяет лидеру, обладающему абсолютной властью действовать в соответствии со своими личными моральными установками, недопускающими угнетения граждан и нарушения их прав и свобод. Иными словами, «не всегда то, что дозволяет политику закон, допустимо с моральной точки зрения, тем более что закон зачастую предоставляет высшим должностным лицам государства очень широкие полномочия и возможность широкого выбора»5. Тем не менее, следует отметить тот факт, что часто именно конфликт между внутренними и внешними регуляторами порождает моральный кризис в обществе, который впоследствии выливается в кризис политический.

Обращаясь к публичной политике, важно отметить, что жизнеспособность и легитимность действующей политической системы зависит, прежде всего,

\footnotetext{
${ }^{3}$ Оболонский А. В. Политическая этика, власть, право // Вопросы гос. и муниц. управления. 2007. Т. 1. №.1. С. 56.

${ }^{4}$ Гусейнов А. А. Мораль и политика: уроки Аристотеля // Ведомости. 2004. №. 24. С. 94.

${ }_{5}^{5}$ Оболонский А.В. Этика публичной сферы // Общественные науки и современность. 2008. № 2. С. 61.
}

от того, насколько политические институты и должностные лица соответствуют принятым в обществе ценностям и идеалам, а также насколько поведение должностных лиц соответствует принятым в обществе нормам морали. Проявление такого взаимодействия властных структур и гражданского общества через призму морали проявляется в принятии Этических кодексов, определяющих поведение и принятие политических решений членами исполнительной и законодательной власти ${ }^{6}$. Резкое привлечение внимание к моральным аспектам государственной службы призвано укрепить доверие граждан к демократическим институтам и аппарату чиновников, поскольку именно доверие является основой демократического политического режима 7 . При этом, эффективное функционирование политической системы, соответствующей принципам морального правления осуществляется в том случае, когда политические институты естественно позволяют людям преследовать свои интересы, пользоваться правами и содействовать этим всеобщему благосостоянию ${ }^{8}$.

Ещё одним важным фактором, определяющим устойчивость политического режима и конкретно популярность политика в общественной среде, являются его личные моральные качества. Наиболее важным с моральной точки зрения является чувство и сознание социальной ответственности за свои действия и слова ${ }^{9}$. Способность политика отвечать за свои действия и выполнять обещания - это часть принципа подотчётности и подконтрольности властвующих элит обществу, то есть основного принципа демократического правления. Вопрос заключается в том, каким образом выбранный политик использует власть и для чего она, в принципе, ему нужна. Честолюбие характерно для политика, но это честолюбие должно быть строго ограничено гражданскими ориентациями, то есть участием граждан в процессе принятия справедливых для общества политических решений ${ }^{10}$. В ином случае

\footnotetext{
${ }^{6}$ Оболонский А. В. Политическая этика, власть, право // Вопросы гос. и муниц. управления. 2007. Т. 1. №.1. С. 80.

${ }^{7}$ Оболонский А. В. Политическая этика, власть, право // Вопросы гос. и муниц. управления. 2007. Т. 1. №.1. С. 81.

${ }^{8}$ Оболонский А.В. Этика публичной сферы // Общественные науки и современность. 2008. № 2. С. 70.

${ }_{9}^{9}$ Оболонский А.В. Этика публичной сферы // Общественные науки и современность. 2008. № 2. С. 59.

${ }^{10}$ Оболонский А.В. Этика публичной сферы // Общественные науки и современность. 2008. № 2. С. 60.
} 


\section{Политика и общество 3 (111) • 2014}

власть становится для политика средством удовлетворения собственных потребностей и самоутверждения, что выливается в абсолютизацию роли власти как актора, способного единолично принимать решения, без гражданского участия, что в свою очередь ведёт к извращению демократических принципов. Именно поэтому на политика, обладающего большими полномочиями, нежели простой гражданин, должно налагаться большее количество ограничений и самоограничений. «Не все практически возможное и достижимое должно быть для политика морально приемлемым» ${ }^{11}$.

Отсутствие моральных ограничителей политических элит ведёт к столкновению личностных убеждений правителя с ценностными ориентациями общества. Это происходит в государствах со слабо развитыми демократическими институтами, либо в странах, где они в принципе отсутствуют, то есть в тех государствах, где не развита система подотчётности правительства обществу и там, где граждане не рассматриваются в качестве реальных участников политического процесса. При этом в таких обществах зарождается культура политического участия. Причина проста: развитие информационного общества, компьютеризация и демократические революции в большом количестве стран в конце XX века, подвигли граждан авторитарных стран требовать от режима изменения своего положения в политической конъюнктуре. Они «больше не согласны удовлетворяться ролями периодических, а зачастую и фиктивных участников политического процесса» ${ }^{12}$. Более того, традиционная патриархальная модель автократий становится архаичной и уже не способна противостоять вызовам современности. Именно демократия может быть лучшим (хоть и не идеальным) гарантом моральной политики, то есть политики, руководствующейся критериями добра и зла, чести и бесчестия, совести и справедливости, то есть той формы власти, которая соотносится с требованиями и устоями общества, которому она должна быть подконтрольна $^{13}$. Важным является и подконтрольность правящей группы ещё одному принципу - соблюдению прав человека, которые защищаются не только рамками

\footnotetext{
${ }^{11}$ Оболонский А.В. Этика публичной сферы // Общественные науки и современность. 2008. № 2. С. 61.

${ }^{12}$ Оболонский А.В. Этика публичной сферы // Общественные науки и современность. 2008. № 2. С. 57.

${ }^{13}$ Оболонский А.В. Этика публичной сферы // Общественные науки и современность. 2008. № 2. С. 58.
}

нормативно-правового регулирования, но и моральной общественной системой ${ }^{14}$. В этом случае власть руководствуется не только формально закреплёнными законами, закрепляющими ценностные ориентиры общества, но и степенью приемлемости принимаемых решений для каждого отдельного человека.

Представляется очевидным, что при анализе различных моделей формирования государственной политики ключевым критерием будет выступать степень открытости данного процесса и характер взаимоотношений между государством и институтами гражданского общества.

Необходимо также отметить ряд дополнительных факторов, влияющих на доминирующую в обществе модель формирования государственной политики. В первую очередь речь идет о господствующем типе представительства интересов - территориальном (партийном) или функциональном (корпоративном). От характера данного фактора будет зависеть степень участия различных политических институтов в процессе формирования государственной политики. Кроме того, важное значение имеет сама конфигурация данных институтов в конкретном обществе (тип партийной системы, характер и степень влиятельности основных общественно-политических организаций, правовое и социальное положение лоббистских структур и проч.).

На 19-м конгрессе Международной Ассоциации политической науки (июль-август 2003 г.) были представлены материалы, в которых рассмотрены две типичные для современных демократий модели интеграции интересов гражданских групп в политический процесс. Одна модель - экспертно-бюрократическая: в самом государственном аппарате действуют структуры, специально занимающиеся анализом кластеров гражданских интересов и транслирующие их в процесс выработки и реализации публичной политики. Вторая модель - демократического участия: гражданские организации сами агрегируют свои предложения и оценки, оказывая давление извне на формирование государственной политики. Первая дает возможность прямого выхода требований общественных групп на государственные механизмы принятия решений, но это таит в себе опасность бюрократического выхолащивания и микширования остроты этих требований.

\footnotetext{
${ }^{14}$ Колотова Н. В. Права человека как сфера взаимодополнения права и морали // Права человека и политическое реформирование. 1997. С. 139.
} 
Вторая модель сильна самостоятельным участием гражданских объединений в политическом процессе, но страдает от отсутствия стабильности и ресурсов. Высказывается мысль о том, что «каждая из моделей мола бы выиграть от более интегрированного «экспертно-консультативного» подхода.

В России уже производились попытки систематизировать политические решения:

Деятельность общественной палата РФ и сети общественных палат по субъектам дала возможность на какую то степень систематизировать деятельность политических органов местного и регионального самоуправления с ведением электронной отчетности;

Комиссия по модернизации при Президенте РФ рассматривает вопросы модернизации экономики в стране и полный контроль по тендерам и госзакупкам; политике и национальных проектов. Всего в орган входит 10 различных комиссий.

Агентство стратегических инициатив дает возможность реализации молодых амбициозных лидеров, как в политическом плане, так и в экономико-организационном.

Организация «Открытое правительство» - создано с целью обнародования политических документов (расход бюджетных средств, экономические стратегии на ближайшие года и т.д.) для открытого гражданского контроля.

Каждая из организаций преследовала инициативы существующей власти, а не вопросы улучшения ситуации в стране и дальнейшей её модернизации. Иными словами, самостоятельных разработок в этом плане не наблюдается, а только показательные работы, поддерживающие существующее правительство и органы местного самоуправления.

Кроме того, осуществление автократической модели моральной политики в России маловероятно по нескольким причинам.

Во-первых, политика государства при авторитаризме определяется лидером, для которого общественное служение и подотчётность гражданам - это миф, порождённый политической демагогией, а власть для них при этом становится гедонистической самоцелью ${ }^{15}$. Иными словами, решения конфликта общественных интересов и базовых ценностей с ценностями и убеждениями лица, находящегося у власти быть не может. Из этого следует тезис о том, что для авто-

${ }^{15}$ Оболонский А.В. Этика публичной сферы // Общественные науки и современность. 2008. № 2. С. 60. ритарного общества характерно превалирование интересов властной элиты над интересами граждан, что и определяет моральный раскол между государством и стремящимися к осуществлению своих прав и учёту своего мнения людьми.

Во-вторых, даже если во главе государства стоит лидер, готовый учитывать ценностные ориентации граждан при принятии каких-либо политических решений и, следовательно, сгладить конфликтную ситуацию, возникает иная проблема. Эта проблема заключается в окружении авторитарного лидера, чьи цели могут быть диаметрально противоположны целям правителя. Для них нахождение у власти - это, прежде всего инструмент решения своих личных или групповых проблем, что и определяет внутреннюю и внешнюю политику государства ${ }^{16}$. Временщики, карьеристы и посредственности, выступающие в качестве советников главы государства, в качестве приближённых, либо аппарата управления, стремятся упрочить свою власть и улучшить своё экономическое и социальное положение за счёт нахождения на позиции вблизи механизма распределения ресурсов. В условиях фактического отсутствия личной привязанности к лидеру при единовременном отсутствии морального кодекса, определяющего и контролирующего политического поведение, рациональной стратегией элиты станет смещение общественно-ориентированного правителя, чьи убеждения представляют реальную угрозу дальнейшему существованию налаженного механизма обогащения и удовлетворения амбиций.

В-третьих, центральным звеном авторитарного государства является практически неконтролируемая и малоэффективная бюрократия, которая будучи единым механизмом, представляет интересы своих отдельных составных частей. При отсутствии этической базы, работа бюрократии направлена не на достижение общественного результата и удовлетворение общественных потребностей, но на воплощение в жизнь амбиций и обогащение отдельных чиновников или клиентилистских групп. Система моральных критериев бюрократии лежит вне общественных интересов, поэтому для неё характерны девиантные действия чиновников, такие как коррупция, корыстолюбие, использование своего положения и своеволие ${ }^{17}$.

\footnotetext{
${ }^{16}$ Оболонский А.В. Этика публичной сферы // Общественные науки и современность. 2008. № 2. С. 58.

${ }^{17}$ Соловьев A. Этика бюрократии: постсоветский синдром // Общественные науки и современность. 1995. №. 4. С. 50.
} 


\section{Политика и общество 3 (111) • 2014}

Вывод: на сегодняшний день единого и универсального института принятия решений в Российской федерации не выявлено. А модернизация требует новых решений. Важно учитывать, что сейчас власть все чаще сталкивается с ситуацией, когда она не в состоянии сама сформулировать запрос на изменения, как это было в момент экономического кризиса, когда только спустя почти полгода были приняты меры по насыщению ликвидностью.

Важно формировать профессиональную технологию оценки общественного мнения, которая позволит государственным органам выбирать уже некоторым образом обсужденный сценарий. Также, важность принятия политических решений, согласованных, прежде всего, с общественным мнением и организациями (не провластными) дает возможность поддержки молодых и перспективных проектов на территории России, а также представляет возможность взаимного диалога между властью и обществом.

\section{Библиография:}

1. Гусейнов А. А. Мораль и политика: уроки Аристотеля // Ведомости. 2004. №. 24. С. 94-128.

2. Колотова Н. В. Права человека как сфера взаимодополнения права и морали // Права человека и политическое реформирование. 1997. С. 139-150.

3. Оболонский А. В. Политическая этика, власть, право // Вопросы гос. и муниц. управления. 2007. T. 1. №.1. С. 79-106.

4. Оболонский А.В. Этика публичной сферы // Общественные науки и современность. 2008. № 2. C. 52-67.

5. Прокофьев А. В. Место и характер моральных аргументов в политической практике (идея «моральной нейтральности» публичной сферы и её альтернативы) // Этическая мысль. 2003. Т. 6. С. 140-162.

6. Соловьев А. Этика бюрократии: постсоветский синдром //Общественные науки и современность. 1995. №. 4. C. 48-57.

7. Сутор Б. Политическая этика // Полис. 1993. №1. C. 61-71.

8. О. В. Алексеева Особенности этапов становления современной российской политической элиты. // Право и политика. - 2012. - 2. - С. 248-256.

9. В.И. Буренко Политический класс современной России в контексте инструментального подхода //
Право и политика. - 2013. - 4. - C. 469-472. DOI: 10.7256/1811-9018.2013.04.3.

10. Г. Л. Акопов Политические элиты России и интернет-сообщество: вопросы взаимодействия // Политика и Общество. - 2011. - 7. - С. 12-21.

11. В.В. Кочетков Российская элитология: наука или идеология? // Политика и Общество. - 2013. - 4. - C. 515-525. DOI: 10.7256/1812-8696.2013.04.18.

12. Волков М.С.. Правящая элита Испании в годы консолидации демократии. // Политика и Общество. - 2013. - № 10. - C. 1302-1313. DOI: $.10 .7256 / 1812-8696.2013 .10 .986$

13. А. В. Войтов, А. П. Галкин. Роль институтов гражданского общества в рекрутировании политических элит в Нижневолжском регионе. // Политика и Общество. - 2011. - № 4.

14. Е.В. Копаева. Губернатор и региональный парламент: борьба за власть в контексте трансформации (случай Ивановской области). // Политика и Общество. - 2011. - № 10. - С. 15-21.

\section{References (transliteration):}

1. Guseinov A. A. Moral' i politika: uroki Aristotelya // Vedomosti. 2004. №. 24. S. 94-128.

2. Kolotova N. V. Prava cheloveka kak sfera vzaimodopolneniya prava i morali // Prava cheloveka i politicheskoe reformirovanie. 1997. S. 139-150.

3. Obolonskii A. V. Politicheskaya etika, vlast', pravo // Voprosy gos. i munits. upravleniya. 2007. T. 1. №.1. S. 79-106.

4. Obolonskii A.V. Etika publichnoi sfery // Obshchestvennye nauki i sovremennost’. 2008. № 2. S. 52-67.

5. Prokof'ev A. V. Mesto i kharakter moral'nykh argumentov v politicheskoi praktike (ideya «moral'noi neitral'nosti» publichnoi sfery i ee al'ternativy) // Eticheskaya mysl'. 2003. T. 6. S. 140-162.

6. Solov'ev A. Etika byurokratii: postsovetskii sindrom //Obshchestvennye nauki i sovremennost'. 1995. №. 4. S. 48-57.

7. Sutor B. Politicheskaya etika // Polis. 1993. №1. S. 61-71.

8. O. V. Alekseeva Osobennosti etapov stanovleniya sovremennoi rossiiskoi politicheskoi elity. // Pravo i politika. - 2012. - 2. - C. 248-256.

9. V.I. Burenko Politicheskii klass sovremennoi Rossii v kontekste instrumental'nogo podkhoda // Pravo i politika. - 2013. - 4. - C. 469-472. DOI: 10.7256/1811-9018.2013.04.3. 
10. G. L. Akopov Politicheskie elity Rossii i internetsoobshchestvo: voprosy vzaimodeistviya // Politika i Obshchestvo. - 2011. - 7. - C. 12-21.

11. V.V. Kochetkov Rossiiskaya elitologiya: nauka ili ideologiya? // Politika i Obshchestvo. 2013. - 4. - C. 515-525. DOI: 10.7256/18128696.2013.04.18.

12. Volkov M.S.. Pravyashchaya elita Ispanii v gody konsolidatsii demokratii. // Politika i Ob- shchestvo. - 2013. - № 10. - C. 1302-1313. DOI: $.10 .7256 / 1812-8696.2013 .10 .986$

13. A. V. Voitov, A. P. Galkin. Rol' institutov grazhdanskogo obshchestva v rekrutirovanii politicheskikh elit v Nizhnevolzhskom regione. // Politika i Obshchestvo. - 2011. - № 4.

14. E.V. Kopaeva. Gubernator i regional'nyi parlament: bor'ba za vlast' $\mathrm{v}$ kontekste transformatsii (sluchai Ivanovskoi oblasti). // Politika i Obshchestvo. - 2011. - № 10. - C. 15-21. 